\title{
Vigilance and Avoidance of Threat in the Eye Movements of Children with Separation Anxiety Disorder
}

\author{
Tina In-Albon • Joe Kossowsky • Silvia Schneider
}

Published online: 8 October 2009

(C) Springer Science + Business Media, LLC 2009

\begin{abstract}
The vigilance-avoidance attention pattern is found in anxious adults, who initially gaze more at threatening pictures than nonanxious adults (vigilance), but subsequently gaze less at them than nonanxious adults (avoidance). The present research, using eye tracking methodology, tested whether anxious children show the same pattern. Children with separation anxiety disorder or no mental disorder viewed pairs of pictures, while the direction of their gaze was tracked. Each picture pair showed one picture of a woman separating from a child, the other picture of a woman reuniting with a child. The results supported the vigilance-avoidance model in children. Although the two groups' gaze direction did not differ during the first second of viewing, anxious children gazed significantly more at separating (threatening) pictures than nonanxious children after a period of $1 \mathrm{~s}$. But after $3 \mathrm{~s}$ the pattern reversed: anxious children gazed significantly less at the separating pictures than nonanxious children.
\end{abstract}

Keywords Attentional bias - Eye movement .

Separation anxiety disorder - Vigilance-avoidance model

Children suffering from separation anxiety disorder (SAD) have excessive and unrealistic fears of being separated from an attachment figure. SAD is one of the most common mental disorders in childhood, and one of the earliestemerging (Cartwright-Hatton et al. 2006; Kessler et al. 2005). SAD is also a risk factor for various mental disorders

T. In-Albon $(\square) \cdot J$. Kossowsky $\cdot$ S. Schneider

Clinical Child and Adolescent Psychology,

University of Basel,

Missionsstrasse 60/62,

4055 Basel, Switzerland

e-mail: tina.in-albon@unibas.ch in adulthood (Brückl et al. 2007; Lewinsohn et al. 2008). Theories of childhood anxiety disorders, including SAD, are generally derived from theories of adult anxiety disorders, which are predominantly cognitive theories emphasizing chronically anxious people's exaggerated concerns about potential threats (Beck et al. 1985; Kendall 1985; Mathews and Mackintosh 1998; Williams et al. 1997).

Threat-related cognition includes not only people's ideas about threat, such as their expectations of harm, but also the way people deploy their attention toward threatening stimuli. Cognitive theories generally predict that because an anxious person is preoccupied thinking about threats (i.e., activities or stimuli that are subjectively threatening to the anxious person but not to a nonanxious person), then he or she should also display threat-related attentional biases, such as attending selectively to threatening information and remaining overly vigilant to detect threat. This vigilance hypothesis would predict, for example, that anxious people are on the average quicker than nonanxious people to detect a threatening stimulus, and more likely, in the presence of threatening stimuli, to be distracted by them from other concerns (e.g., Eysenck 1992; Mathews 1990). Such vigilance has been theorized to be not only an effect of anxiety, but a reciprocal cause of anxiety because selectively attending to threat leads people to overestimate the likelihood or imminence of harm.

In the first few seconds after they encounter a threatening stimulus, anxious adults, anxious children, and people at risk of developing anxiety disorders show threat-directed attentional biases, i.e. vigilance. For example, in the emotional Stroop task people see a colored word that is sometimes threatening and sometimes non-threatening and must name its color as quickly as possible. When the word is threatening, anxious people take longer than their nonanxious counterparts to name its color, presumably 
because their attention is more distracted by the words' threatening meaning (e.g., in adults: Mathews and MacLeod 1985; in children: Martin et al. 1992; Moradi et al. 1999). Similar results have been found using the dotprobe paradigm, in which participants are shown two stimuli, one threatening and the other non-threatening, displayed on the left and right sides of a screen. After a delay, the stimuli are replaced by a dot in one of the two stimuli locations. The time required to indicate on which side the dot appeared allows inferring where the participants' attention was previously deployed. Chronically anxious children and adults are faster than their nonanxious counterparts to indicate the dot's side when it appears on the threatening side, and slower than nonanxious people when the dot appears on the non-threatening side, both patterns supporting the vigilance hypothesis of attention in chronic anxiety (e.g., in adults: MacLeod et al. 1986; in children: Vasey et al. 1995). However, some studies have failed to find vigilance in anxious children (e.g., with the Stroop task: Kindt et al. 2003; Schneider et al. 2008; and with the dot-probe task: Monk et al. 2006; Waters et al. 2004). Nevertheless, enough studies have found it in both children and adults to prove that the vigilance phenomenon is real. But anxious people's attention bias in relation to threat appears to be more complex than uniformly elevated vigilance and that complexity calls for caution in evaluating past emotional Stroop and dot-probe task findings.

The vigilance-avoidance model proposes that anxious people's attention to newly-visible threatening stimuli exhibits both a vigilance bias and its counterpart, an avoidance bias, depending on the timing of the measure of attention in relation to the moment the threat stimulus first becomes visible, i.e., its onset (Mogg and Bradley 1998; Williams et al. 1997). According to this view, both vigilance and avoidance represent attentional biases predicted by the psychological meaning of chronic anxiety and threat (Mogg and Bradley 2006), and from the distinction between early, largely automatic processes in the detection of threat, and later, largely controlled thinking processes in reacting to threat (LeDoux 1996). The vigilance-avoidance model agrees with the vigilance hypothesis that anxious individuals are initially more vigilant to detect threat than nonanxious individuals. But the vigilance-avoidance model further proposes that having detected an anxiety-provoking threat, anxious people will avoid it by diverting their attention from it. The vigilance-avoidance model thus predicts that anxious people will at first gaze longer at a newly visible threatening stimulus than nonanxious people, but thereafter the pattern will reverse and anxious people will gaze less at the threatening stimulus than nonanxious people. The vigilance-avoidance pattern has important possible implications for the development and maintenance of fears and anxiety. If overly vigilant gaze increases anxiety by leading people to overperceive threat and hence to overestimate danger, then the subsequent avoidant gaze could maintain or increase anxiety by preventing the person from realizing that their perception of threat is exaggerated and by preventing the person from extinguishing the anxiety by exposing themselves to the threat rather than avoiding it. An anxiety-maintaining effect of gaze avoidance would be consistent with a large body of research showing that avoidant behavior in anxious people tends to maintain their anxiety, whereas counter-avoidant behavior and counter-avoidant thinking and imagining tend to reduce their anxiety (e.g., Grawe et al. 1994). If the vigilanceavoidance model is correct, then past experimental failures in finding attention biases might have arisen not from the absence of bias, but because the experimenters sampled people's attention at a moment when bias was not taking place. The vigilance-avoidance model is not specific as to whether there should be an initial orienting period when anxious and nonanxious adults or children will fail to show vigilance, nor as to the exact timing of the transition point from vigilance to avoidance, a point when attention to threat will not differ between anxious and nonanxious people. The transition should presumably occur when people's recognition and controlled thinking come into play. Therefore, measuring anxious and non-anxious people's attention over time and testing the vigilanceavoidance model requires monitoring their attention at frequent intervals over the first several seconds after threatening stimuli come into view. The emotional Stroop task appears limited to capturing attention biases very early after the onset of the threatening word, as the participant names its color as quickly as possible. The dot-probe paradigm allows for the delaying of the dot-probe until several seconds after the new threat stimulus comes into view, so that by systematically varying the delay the technique can be used to map the time course of people's attention to a new threatening stimulus. However, such research would require many presentations of threat stimuli with varying delays of the dot-probe, a procedure that is feasible but cumbersome and has not as yet been done with children.

A superior method of testing the possibly extended and varying time course of anxious people's attention biases in relation to threatening stimuli is eye tracking (Bögels and Mansell 2004). In eye tracking, the individual simply views stimuli on a screen, while the assessor unobtrusively and continuously records the exact position of the person's eye gaze. The participant needs do nothing but look at the stimuli. The assumption is that the direction of gaze is closely linked to what is being attended to (Just and Carpenter 1976). With eye tracking, anxious people's attentional biases can be measured by having them view threatening or nonthreatening stimuli presented singly or in 
contrasting (or opposing) pairs, with gaze time at the threatening stimulus serving as the measure of attention to threat.

Eye tracking research with anxious adults has tended to support the vigilance-avoidance model (Garner et al. 2006; Mogg et al. 2000; Pflugshaupt et al. 2005; Rinck and Becker 2006), although some studies found only partial support for it, finding avoidance but not vigilance (e.g., Hermans et al. 1999; Rohner 2002). Most studies that found a vigilance effect using pairs of stimuli, one threatening and the other neutral, which MacLeod and Mathews (1991) judged to be more likely to show the effect than would singly-presented stimuli. The authors suggest that the cognitive effect of anxiety may be described as a priority for the processing of certain stimuli. Because of the limited processing capacity, this has a negative effect on the processing of other information.

It is important and remains to be seen if children display the same vigilance-avoidance pattern as adults. Monk et al. (2006) found that the relationship between anxiety and attentional biases for threat varies across development, a finding that necessitates examining threat-related attentional biases directly in children and adolescents. The vigilanceavoidance model has not previously been investigated in anxious children, nor has children's attention toward threat been evaluated yet with eye tracking methods. Adult studies have typically examined gaze toward simultaneously presented pairs of stimuli, one of which is threatening and the other neutral. Given that children are more likely than adults to experience fatigue, we found it advantageous to make the pairs of stimuli as contrasting as possible, thus pairing threatening images with their opposites. Studies assessing adults with anxiety disorders mostly found an immediate vigilance effect. However, adults and children could differ, for example given children's lesser cognitiveperceptual maturity. Therefore, the vigilance effect may not occur as immediate as in adults but with a short delay of time, in which children process the stimuli. However, since there is at current no research on this issue, we were not able to formulate a stricter hypothesis. We therefore decided to predict that the vigilance may occur either immediately or after an initial orientation period.

Our hypothesis was that anxious children would show the vigilance-avoidance pattern. Children with SAD and children with no disorder viewed a series of pairs of photographs, one of which depicted a child separating from an adult woman (the threat picture), the other a child reuniting with an adult woman. We measured the duration of the children's gaze at each of the two pictures during the first $4 \mathrm{~s}$ each pair was in view. We predicted that the children with SAD would demonstrate vigilance either immediately or after an initial orienting period by gazing longer at the separating pictures than the nonanxious children, but would thereafter demon- strate avoidance by gazing less at the separating pictures than the nonanxious children.

\section{Method}

\section{Participants}

Participants were 23 children with a primary DSM-IV-TR diagnosis of SAD (13 girls and 10 boys) and 17 nonanxious control children (6 girls and 11 boys). The mean age of the children with $\mathrm{SAD}$ was 9.91 years $(\mathrm{SD}=1.44$, Range $=8-13)$ and of the nonanxious control children $10.29(S D=1.40$, Range 8-13). The groups were comparable with respect to age $(t(38)=0.84, p=0.41)$ and gender $\left(\chi^{2}(1, N=40)=1.77\right.$, $p=0.18$ ). The sample size provided $87 \%$ power to detect a medium effect size (Cohen's $d=0.50$ ). Of the children in the SAD group, $10(43.5 \%)$ met criteria for one additional clinical disorder (generalized anxiety disorder, social phobia, specific phobia, or insomnia). The nonanxious control group never experienced any mental disorders when assessed with the Kinder-DIPS. The children with SAD were participants in a cognitive-behavioral treatment study of SAD at the University of Basel, Switzerland, but had not completed any treatment program before taking part in this study. The children were recruited by referral from child health professionals and by parents who self-referred their child in response to announcements on the Internet, in local newspapers and magazines, in schools, and in family centers in the Basel area. Nonanxious children were paid for participation. The SAD and nonanxious children were markedly dissimilar in their level of separation anxiety, as shown by nonoverlapping distributions in their scores on the parent report of SAD, to be described in detail in the "Measures" and "Experimental Checks" subsection of the "Method" section, below.

\section{Procedure}

Children and their parents gave written consent to participate in the research project, approved by the Ethics Committee of Basel, Switzerland, which informed them of the child's right to withdraw at any time. No child withdrew from participation. Children were tested individually in a quiet room with the assistance of a graduate student. Both the child and the parent completed a diagnostic interview and questionnaire measures that were gathered to confirm that the two groups differed in chronic anxiety as intended.

\section{Measures}

Diagnoses of Mental Illness To examine the children's current or past DSM-IV-TR diagnoses, we conducted a 
structured interview of each child and, separately, of each child's parents (i.e., either the mother or father or both together). Children's mental illnesses were diagnosed using a structured interview, the Diagnostic Interview for Mental Disorders in Children and Adolescents (Kinder-DIPS; Schneider et al. 2009), which has alternate forms for child and parent. The structured interview assesses all anxiety disorders, depression, attention-deficit hyperactivity disorder, oppositional defiant disorder, sleep disorders, eating disorders, and elimination disorders. The Kinder-DIPS has good validity and reliability for anxiety disorders (child version: kappa $=0.88$; parent version: $k a p p a=0.85$ ) and other axis I disorders (child version, kappa $=0.48-0.88$, parent version, kappa $=0.85-0.94$; Schneider et al. 2009). Diagnoses were based on composite information from the two separate child and parent interviews. Doctoral students in clinical child psychology were first systematically trained in conducting the interviews. SAD was diagnosed if either interviewer rendered the diagnosis.

Separation Anxiety, Child Rating Children completed the Separation Anxiety Inventory for children (SAI-C; Scalbert, M., In-Albon, T., \& Schneider, S. (2006). Psychometrische Gütekriterien des Trennungsangst-Inventars für Kinder [Psychometric properties of the Separation Anxiety Inventory]. Unpublished Master Thesis, University of Basel.), a questionnaire consisting of 12 items assessing the degree to which the rater avoids 12 different separation situations. The stem of each item is "Because I am anxious, I'm avoiding... e.g., going to school, sleeping in my own bed". The psychometric properties of the SAI-C were good, including its internal consistency (alpha $=0.85$ ), its testretest reliability $(r=0.84)$, and its construct validity covering all the major features commonly used to define separation anxiety disorder (Scalbert et al. 2006).

Separation Anxiety, Parent Rating Parents rated the Separation Anxiety Inventory for parents (SAI-P; Brugger, M., Schneider, S., \& In-Albon, T. (2006). Psychometrische Gütekriterien des Trennungsangst-Inventars für Kinder, Elternversion [Psychometric properties of the Separation Anxiety Inventory, parent version]. Unpublished Master Thesis, University of Basel.), which assesses the parent's view of the degree to which the child avoids the same 12 separation situations as in the child version. Internal consistency of the current sample was alpha $=0.88$.

Manifest Anxiety, Child Rating Children rated their manifest anxiety by completing the Revised Children's Manifest Anxiety Scale-Child version (RCMAS; Reynolds and Richmond 1978; German Version; Boehnke et al. 1986), a self-report measure with 37 items. Cronbach's alpha for the German version of the current sample was 0.98 .
Manifest Anxiety, Parent Rating Parents rated their child's manifest anxiety by completing the Revised Children's Manifest Anxiety Scale-Parent version (RCMAS-P; Pina et al. 2001; German version: Schneider, S., Adornetto, C., \& Blatter, J. (2004). Revised Children's Manifest Anxiety Scale-Parent version (RCMAS). Unpublished manuscript, University of Basel.), which has items identical to those of the child rating version except that each item's stem was changed from "I..." to "My child...". Internal consistency of the German version and the current sample for the total anxiety scores were 0.86 .

Depression The children indicated their level of depressed mood by completing the Children's Depression Inventory (CDI; Kovacs 1981; German Version DIKJ, StiensmeierPelster et al. 2000), a self-report measure of depression for children and adolescents. Depressed mood is often associated with chronic anxiety among both children and adults. The CDI includes 26 items sampling the cognitive, affective and behavioral signs of depression; children indicate whether each item characterizes themselves during the past 2 weeks. The German version of the CDI in the current sample had an internal consistency of 0.96 .

Children's State Anxiety Because high levels of state anxiety are associated with increased threat perception and lower threat thresholds (MacLeod 1990; Muris et al. 2003), we assessed children's level of state anxiety before and after the eye tracking procedure. Using paper and pencil, each child indicated his or her current anxiety on a $0-10$ point Likert scale ranging from "I am not at all anxious" to "I am very anxious." The purpose was to allow judging whether experimental effects might have been affected by state anxiety differences, not only by chronic anxiety differences, between the two groups of children.

\section{Assessment of Vigilance and Avoidance}

Stimulus Materials: Separating and Reuniting Photographs Because we investigated a homogeneous group of children with respect to SAD, we could use images of a woman separating from a child as threat stimuli for all anxious children, an action children with SAD find threatening and anxiety-provoking, and we could use images of a woman reuniting with a child as potent non-threat stimuli. A match between stimuli and the specific anxiety disorder is recommended by Mogg and Bradley (1998) and Öhman et al. (2001) for researching biased attentional processes in anxiety. Attentional biases are more likely in situations that involve the presentation of multiple stimuli competing for attention (e.g., MacLeod and Mathews 1991). Therefore, we created color photographs representing separating situations and reuniting situations. Separating photographs 
depicted a child and a woman, apparently the child's mother, separating from one another, e.g., by the woman leaving home or driving away in a car. Reuniting pictures depicted the child and woman greeting and embracing one another. The child in the photograph was either a boy or a girl, to allow matching the gender of the child in the photograph to the gender of the participant. Children in the pictures were between 8 and 10 years of age. Thus, children in the pictures were at a comparable age as the children we investigated in this study.

Pretesting of the Stimulus Photographs The intended apparent difference between the separating and reuniting photographs was pretested in a preliminary study with 253 unselected school children, none of who took part in the present study (In-Albon et al. 2008). In the preliminary study children rated a set of 15 separating and 15 reuniting pictures using a 9-point Likert scale ranging from " 1 = definite reuniting" to " $9=$ definite separation". The pretest children correctly rated the pictures at near opposite ends of the separation scale (reuniting photographs, $M=1.33, S D=$ 0.74 ; separating photographs, $M=7.91, S D=1.5$ ). The pictures for the present experiment were selected from the preliminary set and had been rated similarly by girls and boys in the preliminary study (In-Albon et al. 2008).

Final Eight Stimulus Slides Having pretested the photographs as effective images of separating and reuniting, we then used the pretested photographs in creating a set of 8 slides, each slide containing two target photographs, displayed left and right, one depicting a separating scene and the other a reuniting scene, matched for complexity and brightness. Shown in Fig. 1 is an example of a slide. The left-right position of the separating and reuniting photographs was counterbalanced randomly across trials. All pictures had a size of $600 \times 450$ pixels and were presented on a computer screen with a resolution of $1,024 \times 768$ pixels.

Eye Tracking Apparatus We tracked participants' gaze direction with the Tobii 1750 table-mounted eye tracker (Tobii Technology AB. (http://www.tobii.com, Sweden), which consists of a computer screen (an LCD flat panel display) with a camera and infrared LED optics embedded beneath it. Each stimulus slide containing a pair of photographs was displayed on the computer screen while data recording participants' gaze direction were collected for both eyes simultaneously on an average of every $20 \mathrm{~ms}$ (i.e., $50 \mathrm{~Hz}$ ) and at an accuracy of less than $0.5^{\circ}$ (bias error). This eye tracker is characterized by the unobtrusiveness of its hardware, which promotes natural behavior by not restricting participants with helmets or head/chest-rests, nor does it require removal of eyeglasses (In-Albon and
Schneider 2009). The software package "ClearView", provided by Tobii, was used with the Tobii 1750 to examine the child's eye movements by means of a posthoc analysis of the visual fixations within the two target pictures. The eye tracking data were then examined in terms of fixations recorded within these pictures (areas of interest). Fixations were counted if they were longer than $20 \mathrm{~ms}$ on the defined area of interest. Mean latencies for each picture type were calculated after excluding latencies exceeding 3 SD above each participant's mean.

Eye Tracking Procedure Participants were seated approximately $60 \mathrm{~cm}$ away from the computer monitor. The instruction given to the child was: "Your task will be to look at the pictures on the screen until they disappear; move your eyes, but not your head". An experimenter who was unaware of whether the child had SAD sat in the room with the child to ensure that the child paid attention to the screen, and that the eye tracker was working properly. After calibration, a single picture pair was shown for $4 \mathrm{~s}$. Prior to each picture display, a central fixation cross was shown for $1,000 \mathrm{~ms}$ in order to catch the participants' attention. The intertrial interval varied randomly within each block of trials between $750 \mathrm{~ms}$ and 1,250 ms. The pairs of pictures were presented in counter balanced order across trails, one on the left side and the other on the right side of the screen. Each child underwent 9 blocks of trials, with each block containing 8 trials (i.e., eight 4 -second presentations of a picture pair). The paradigm lasted about $20 \mathrm{~min}$.

The procedure effectively gathered eye tracking data. Both groups of children spent an average of $66 \%$ of their time looking at the photographs, i.e., either at the separating or the reuniting photograph, and the two groups did not differ significantly in total photograph viewing time. The balance of $34 \%$ was spent viewing elsewhere than the pictures. This $34 \%$ did not include errors of eye tracking accuracy.

\section{Experimental Checks}

Intergroup Differences in Chronic Anxiety The two child groups differed as expected in separation anxiety. Presented in Table 1 are the mean scores of SAD and nonanxious children on the various questionnaire measures. Children with SAD scored significantly higher on the disorderspecific Separation Anxiety Inventory than nonanxious children, including both the Child form (SAI-C) and Parent form (SAI-P). In the parent completed RCMAS-P measure, children with SAD were rated as being significantly more anxious.

Ratings of Photograph Content, Valence, and Arousal After the eye tracking procedure, we had each participant rate 
Fig. 1 Separation-related photographs (reuniting, separating)
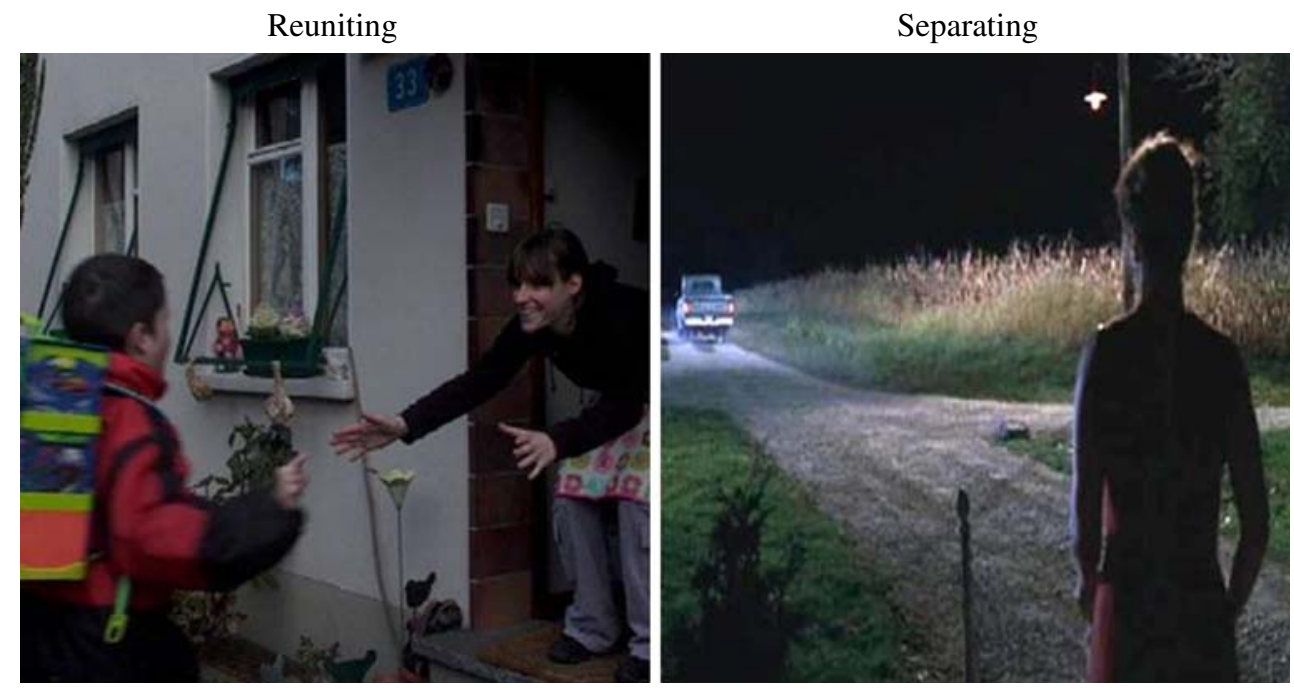

each of the 16 photographs on the 8 stimulus slides for the extent to which it showed a separating scene or a reuniting scene, using a 9-point Likert scale ranging from 1 ("definite reuniting") to 9 ("definite separating"). In addition, participants rated each picture's valence and arousal using the Self-Assessment Manikin, a pictorial 9-point scale (SAM; Bradley and Lang 1994) ranging from "very pleasant" to "very unpleasant" for valence from "excited" to "calm" for arousal. Children were told to make a written mark for valence and then for arousal either on or between the anchoring figures for each scale.

Like the children in the preliminary check reported above, the present participants rated the pictures' content appropriately as separating or reuniting. Their mean valence, arousal, and picture ratings are presented in Table 2. Low scores indicate that the child rated the picture as reuniting and high scores indicate that the child rated the picture as separating. The two groups' ratings did not differ from one another for either type of photograph.

The two groups of children rated the photographs' valence and arousal as expected. A two-way (Group $\times$ Picture Type) mixed ANOVA was performed to check whether children with SAD reporter higher levels of arousal and valence, irrespec- tive of picture content. For both the valence ratings and the arousal ratings, the Group $\times$ Picture Type interaction was not significant, (valence ratings: $F(1,37)=3.17, p=0.08$; arousal ratings: $F(1,37)=0.23, p=0.63)$. Thus, children with $\mathrm{SAD}$ were not generally more aroused by the photographs than nonanxious children, and the group differences in their ratings for each picture type can be attributed to picture content. Separate analyses of each picture type showed that, as expected, children with SAD rated separating photographs' valence as significantly more unpleasant than did nonanxious children, $t(37)=2.88, p<0.01$. Children with SAD found separating photographs more arousing than did the nonanxious children, $t(37)=3.08, p<0.01$, as well as the reuniting photographs, $t(37)=3.07, p<0.01$. In short, the photographs elicited an emotional response, especially in children with SAD.

State Anxiety in Relation to Eye Tracking State anxiety assessed on the $0-10$ scale before and after eye tracking procedure was very low in nonanxious children $(M=0.07$, $S D=0.26)$ and in children with $\operatorname{SAD}(M=0.24, S D=0.54)$ and it remained low after the procedure in both nonanxious children $(M=0.00, S D=0.00)$ and children with $\operatorname{SAD}(M=$

Table 1 Mean Anxiety and Depression of Children with SAD and of Nonanxious Children

\begin{tabular}{|c|c|c|c|c|c|c|c|}
\hline \multirow[t]{2}{*}{ Questionnaire } & \multirow[t]{2}{*}{ Range } & \multicolumn{2}{|l|}{ SAD } & \multicolumn{2}{|c|}{ Nonanxious } & \multirow[t]{2}{*}{$t(34)$} & \multirow[t]{2}{*}{$p$} \\
\hline & & M & SD & M & $\mathrm{SD}$ & & \\
\hline SAI-C & $0-48$ & 22.9 & 9.5 & 8.1 & 8.8 & 4.69 & $<0.001$ \\
\hline SAI-P & $0-48$ & 26.3 & 9.5 & 7.8 & 6.6 & 6.67 & $<0.001$ \\
\hline RCMAS-C & $0-37$ & 11.7 & 7.2 & 8.1 & 5.0 & 1.64 & $=0.11$ \\
\hline RCMAS-P & $0-37$ & 13.1 & 4.6 & 5.5 & 4.6 & 4.62 & $<0.001$ \\
\hline CDI & $0-52$ & 10.8 & 6.9 & 7.9 & 6.0 & 1.28 & $=0.21$ \\
\hline
\end{tabular}

SAI Separation Anxiety Inventory, Child and Parent version; CASI Child Anxiety Sensitivity Index; RCMAS-C Reynolds Children's Manifest Anxiety Scale, Child version; RCMAS-P Reynolds Children's Manifest Anxiety Scale, Parent version; $C D I$ Children's Depression Inventory 
Table 2 Mean Picture, Valence, and Arousal Ratings of Separating and Reuniting Pictures by SAD and Nonanxious Child Groups

\begin{tabular}{|c|c|c|c|c|c|c|c|c|c|c|c|c|}
\hline \multirow{3}{*}{ Picture } & \multicolumn{4}{|c|}{ Picture rating } & \multicolumn{4}{|c|}{ Valence rating } & \multicolumn{4}{|c|}{ Arousal rating } \\
\hline & \multicolumn{2}{|c|}{ SAD } & \multicolumn{2}{|c|}{ Nonanxious } & \multicolumn{2}{|l|}{ SAD } & \multicolumn{2}{|c|}{ Nonanxious } & \multicolumn{2}{|l|}{ SAD } & \multicolumn{2}{|c|}{ Nonanxious } \\
\hline & $\mathrm{M}$ & $\mathrm{SD}$ & $\mathrm{M}$ & $\mathrm{SD}$ & $\mathrm{M}$ & $\mathrm{SD}$ & $\mathrm{M}$ & $\mathrm{SD}$ & $\mathrm{M}$ & $\mathrm{SD}$ & $\mathrm{M}$ & $\mathrm{SD}$ \\
\hline Separating & 8.3 & 1.3 & 8.1 & 1.2 & $* * 5.6$ & 2.2 & 3.4 & 2.5 & $* * 6.4$ & 2.0 & 8.2 & 1.5 \\
\hline Reuniting & 1.3 & 1.2 & 1.2 & 0.7 & 2.1 & 1.4 & 1.4 & 0.9 & $* * 7.1$ & 2.1 & 8.7 & 0.6 \\
\hline
\end{tabular}

Picture rating: 1 = definitely reuniting, $9=$ definitely separation, Valence rating: $1=$ very pleasant, $9=$ very unpleasant; Arousal rating: $1=$ excited, $9=$ calm, *Indicating significant $t$ tests, $p<0.05, * * p<0.001$

$0.23, S D=0.69)$. A $2 \times 2$ ANOVA of these means yielded no significant effects or interactions, $F(1,34)=0.15, p=0.7$. This check thus established that any difference in the eye gaze pattern that might emerge between the two groups of children are not likely be attributable to differences in the children's state anxiety aroused by the procedure itself.

\section{Results}

\section{Vigilance and Avoidance in Children's Gaze}

The findings strongly supported our hypothesis that the time course of relative attention allocation toward threat would differ between chronically anxious children and nonanxious children, and in particular that anxious children would deploy their attention first vigilantly, then avoidantly, as the vigilance-avoidance model predicts. The extent of each child's attention to threat was calculated as the percent of time the child spent looking at separating pictures as a function of total time he or she spent looking at either the separating or the reuniting picture. The means of these bias scores $^{1}$ by each child group over the $4 \mathrm{~s}$ of viewing time, subdivided into eight $500 \mathrm{~ms}$ intervals, are presented graphically in Fig. 2. To test whether attention to threat is biased in children with SAD, we analyzed these means using a 2 (Child Group: SAD and nonanxious) $\times 8$ (Time Interval, ending at: $500 \mathrm{~ms}, 1,000 \mathrm{~ms}, 1,500 \mathrm{~ms}, 2,000 \mathrm{~ms}$, $2,500 \mathrm{~ms}, 3,000 \mathrm{~ms}, 3,500 \mathrm{~ms}$, and $4,000 \mathrm{~ms}$ ) mixed ANOVA with repeated measures on the Time Interval factor. The degrees of freedom and significance levels were adjusted according to the Greenhouse-Geisser correction. The results showed a significant main effect of Time Interval, $F(4.1,141)=2.63, p<0.05$, and, of key importance, a significant Child Group $\times$ Time Interval interaction, $F(4.1,506.9)=3.32, p<0.01$, the latter confirming that the children with SAD allocated their attention to threat over

\footnotetext{
${ }^{1} \mathrm{We}$ are grateful to one of the anonymous reviewers for this suggestion.
}

time differently than did the nonanxious children. The meaning of this significant interaction and its support for the vigilance-avoidance model are evident from visual inspection of Fig. 2. The Figure shows that in the first second the two groups did not differ in their gaze patterns, but from 1 to $2 \mathrm{sec}$, the children with SAD showed the vigilance pattern by gazing relatively longer at threatening stimuli than did nonanxious children. Then between 2 and $3 \mathrm{sec}$ the groups did not differ. Then between about 3 and $4 \mathrm{sec}$ the children with SAD showed the avoidance pattern by gazing relatively shorter at threatening stimuli than did nonanxious children.

The preceding analyses were based on bias scores calculated as the relative amount of time each child gazed at the two pictures. It is also of interest to see each group's absolute viewing time separately at each type of photograph, separating and reuniting, at each time interval, because these absolute scores provide an alternative means of testing the vigilance-avoidance model. Displayed in Table 3 are the mean milliseconds of gaze by children with SAD and by nonanxious children at the separating photographs (the upper half of Table 3) and at the reuniting photographs (the lower half of Table 3), by time periods after picture onset. The last line of the upper half and of the lower half of Table 3 present the effect sizes of the comparison between child groups at each time interval. The complete 2 (Child Group: SAD and nonanxious) $\times 2$ (Picture Type: separating or reuniting) $\times 8$ (Time Interval: ending at $500 \mathrm{~ms}, 1,000 \mathrm{~ms}, 1,500 \mathrm{~ms}, 2,000 \mathrm{~ms}, 2,500 \mathrm{~ms}$, $3,000 \mathrm{~ms}, 3,500 \mathrm{~ms}$, and 4,000 ms) ANOVA of the means in Table 3, with repeated measures on the Time Interval and Picture Type factors, yielded a significant three-way interaction, $F(4.4,154.9)=3.20, p=0.01$, which is consistent with the significant two-way interaction of the relative bias scores reported in the preceding paragraph, as both indicate that the time course of attention to the two photographs differed between the two child groups, with the means showing the patterns of difference to be consistent with the vigilance-avoidance model.

The covariates gender and age did not explain a significant proportion of the variance. 
Fig. 2 Bias scores showing the percentages of time spent looking at separating pictures as a function of total time gazing at both pictures at each $500 \mathrm{~ms}$ interval

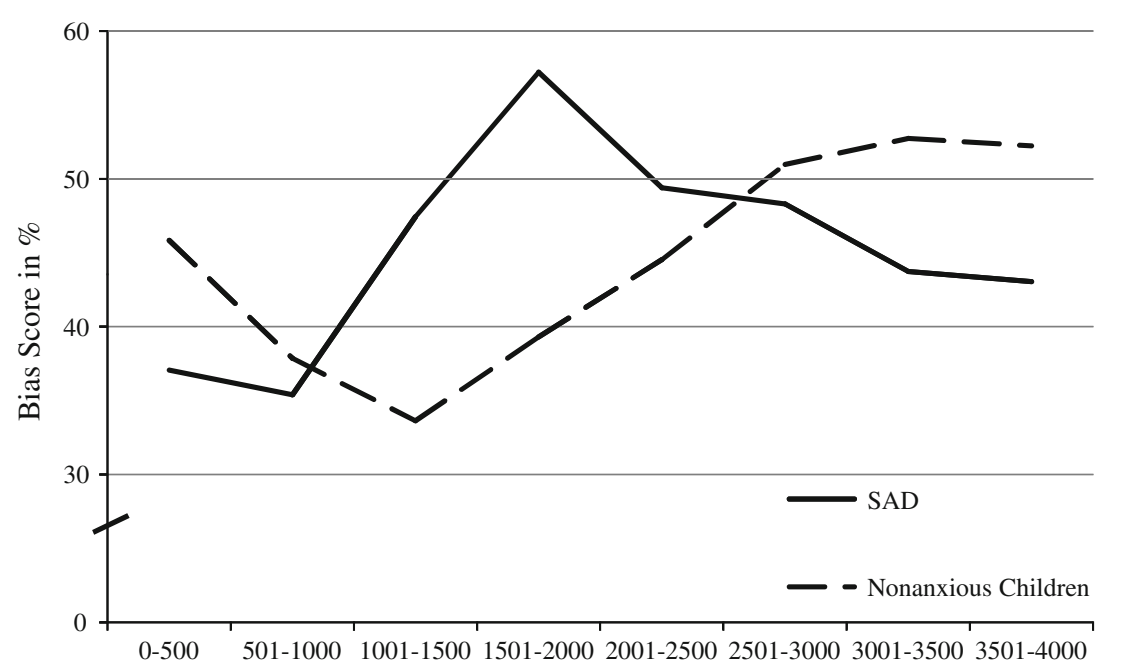

\section{Direction of Initial Gaze}

The first picture fixations were recorded for each child. Both groups first fixated on reuniting photographs. Children with SAD first fixated on reuniting photographs in $76.2 \%$ of trials, while nonanxious children first fixated on reuniting photographs in $76.5 \%$ of trials, thus revealing no significant differences between the groups in initial gaze direction.

\section{Discussion}

Children with SAD are, after an initial second, vigilant for stimuli they find threatening, but once they detect a threatening stimulus, they quickly become avoidant of it. The children might spend the first second judging the meaning of these pictures. After the initial second, children with SAD spent more time than did nonanxious children looking at the separating (threatening) photographs, but after $3 \mathrm{~s}$, children with SAD spent less time than did nonanxious children looking at the separating photographs. This finding is consistent with findings with anxious adults, and it strongly supports the vigilance-avoidance model. Of particular importance is that it shows that the vigilance-avoidance anxious gaze pattern is evident already in preadolescent children with SAD. Therefore, our results point to a remarkable continuity in attentional processes associated with anxiety across the lifespan, highlighting the importance of cognitive processes for emotional disorders. Because of the potential long-term impact that attentional bias might have on the trajectory of disorders, information processing is of particular interest in children.

We believe this is the first study to empirically test the vigilance-avoidance model in children with anxiety disorders, and the first to study the visual attention of children with SAD using eye tracking. It is also the first study on attentional bias in SAD children to examine a diagnostically homogeneous group, and to empirically validate separation-related pictorial images as stimuli. Salient and disorder-specific stimulus materials are important conditions in the assessment of cognitive biases. Previously, most studies assessing cognitive biases in children with anxiety disorders have used diagnostically inhomogeneous groups and exposed them to general threatening material (e.g., Bögels et al. 2003; Bögels and Zigterman 2000; Dalgleish et al. 2003; Muris et al. 2000; Vasey et al. 1995; Waters et al. 2004) instead of material specific to the anxiety disorder each participant suffers from (e.g., In-Albon et al. 2008; In-Albon et al. 2009). However, the content of people's dysfunctional ideas, interpretations, and expectations is thought to be specific to the stimuli or activities each person fears (Beck et al. 1985). Insight into the disorder-specific cognitive and attentional biases of children with anxiety disorders is needed to better understand those disorders, and to develop more effective treatments than those currently available (In-Albon and Schneider 2007). Because the vigilance-avoidance model has been found in adults with other anxiety disorders, the present results might therefore well be generalizable to children with other anxiety disorders. Of course, one cannot be certain of this fact until the vigilance-avoidance model has been actually investigated in children with other anxiety disorders or other disorders. Studies on the specificity of the attentional bias in children are rare and have so far yielded unclear results (Dalgleish et al. 2003; Kindt et al. 2003). Therefore, in a first step, the vigilance-avoidance model was investigated in a group of children with the same anxiety diagnosis in comparison to children without mental disorders. Clearly, the next step would consist of including a second clinical group to test for specificity of the results.

Unlike studies by Pflugshaupt et al. (2005) and Rinck and Becker (2006) with adults that observed the vigilance effect from the first onset of the threat stimulus, we found the vigilance effect only after $1 \mathrm{~s}$ had elapsed. The children 


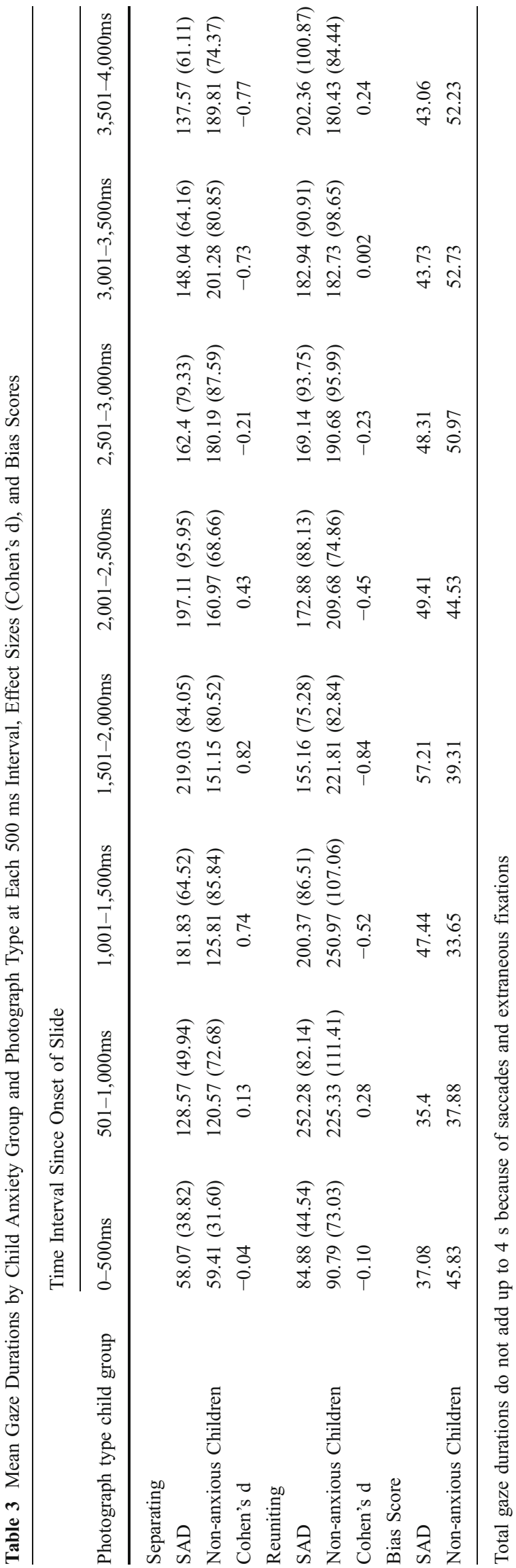

with SAD showed no vigilance bias during the first second of viewing the stimuli, meaning that the percent of their gaze time spent looking at the separating (threatening) stimuli did not differ from that of nonanxious children. A salient possible explanation lies in the complexity of our photographs. Eye movement studies of the vigilanceavoidance hypothesis with anxious adults frequently investigated spider phobic people and used spider pictures as stimuli (Pflugshaupt et al. 2005; Rinck, and Becker 2006). Our pictures depicted interpersonal interactions, the content of which arguably require more time to interpret. A second possible factor that we cannot rule out is that the initial lack of attention bias is a developmental difference between anxious adults' and anxious children's attentional and gaze control processes.

After the initial period, children with SAD displayed the expected vigilance effect, first lingering on the separation photographs. The prolonged early gaze time toward threat observed both in anxious adults and anxious children might reflect a kind of a reassurance seeking behavior. Yiend and Mathews (2001) suggested that when only limited information about a threat is available, highly anxious people are more likely to attend to the threat location and may thus want to learn more about it, to be sure to identify whether it is dangerous or not. But after this early rapid vigilance, anxious people show a later relative avoidance of threat stimuli compared with nonanxious people, possibly reflecting a cognitively controlled instrumental act to reduce the distress threat stimuli evoke in them.

In keeping with the vigilance-avoidance model's labeling and with the methods that have been used to test it, we call the lesser gaze time at threatening stimuli by anxious than nonanxious children "avoidance". In this approach, the nonanxious children provide the standard of what is normal or usual, compared to which a significant deviation is either more than normally vigilant or more than normally avoidant. Important to future research on biases in attention to threat will be exploring the role of controlled versus automatic processes in vigilance and avoidance.

The vigilance-avoidance pattern has been proposed as a key factor in maintaining anxiety. Avoidance is held to maintain anxiety by preventing the individual from evaluating vague stimuli sufficiently to perceive that they are not threatening, and from remaining exposed to threatening stimuli long enough to habituate to, or extinguish, their fear-arousing properties. We are currently investigating whether the vigilance-avoidance pattern in children with SAD changes from before to after treatment with cognitive-behavioral therapy.

Results of the check of how the children perceived the pictures indicated that the separation pictures trigger an emotional state, especially in children with SAD. The ratings of the pictures confirmed that the children were accurate in 
correctly identifying the pictures' content. Children with SAD rated the separating photographs as significantly more unpleasant and more arousing than did nonanxious children, and the pictures children saw as positive (reuniting) were more pleasant and calming than were pictures seen as negative (separating). These results indicate that the stimulus material was valid, but future studies should exclude that attention biases are specific to threatening stimuli and cannot be found for negative pictures in general in children with SAD or other anxiety disorders. An intriguing possible future research methodology is the use of videos.

The present results indicate that attentional biases regarding threat are present in children, but not from where these biases come. One possibility for the development of cognitive biases is that genetically based individual difference variables increase the proneness to cognitive biases (Hadwin et al. 2006). The personality trait neuroticism and the temperament style behavioral inhibition have been proposed as etiological factors, an association between neuroticism and attention bias was found in a cross-sectional study (Hadwin et al. 1997; see also Lonigan et al. 2004).

Field (2006) showed that fear information creates attentional biases toward a threatening stimulus in children and that fear information itself might be sufficient to create anxiety (Field and Lawson 2003; 2008).

The current findings need to be considered in light of some limitations. Despite the advantages of the eye tracking method, humans can voluntary dissociate their attention from the foveal direction of gaze. An eye tracker cannot track the covert movement of visual attention. It remains to be examined whether covert components of attention would alter our estimate of the vigilance-avoidance attentional processes revealed by overt eye movements. An advantage of future research of having a larger sample size would permit testing if there are any age effects in vigilance-avoidance.

The present findings of a different pattern of attention allocation in children with SAD compared to nonanxious children support the vigilance-avoidance model. This might have clinical treatment implications for anxious children, because biased attention is widely theorized to affect development of diverse mental disorders in children. Eye tracking methodology in particular is a promising new method of assessing, and potentially even of treating, cognitive biases in children, as it is easy to administer and visual images can be used as stimuli, which are more ageappropriate for young children than are words.

Acknowledgments We thank S. Lloyd Williams for his helpful comments on earlier versions of this manuscript.

This study was supported by grant project PP001-68701; 105311116517/1) awarded to Silvia Schneider by the Swiss National Science Foundation. We appreciate the participants in this study, as well as the research assistants and graduate students on the project at Universität Basel for their assistance in data collection and management.

\section{References}

Beck, A. T., Emery, G., \& Greenberg, R. L. (1985). Anxiety disorder and phobias: A cognitive perspective. New York: Basic Books.

Boehnke, K., Silbereisen, R. K., Reynolds, C. R., \& Richmond, B. O. (1986). What I think and feel-German experience with the revised form of the children's manifest anxiety scale. Personality and Individual Differences, 7, 553-560.

Bögels, S., \& Zigterman, D. (2000). Dysfunctional cognitions in children with social phobia, separation anxiety disorder and generalized anxiety disorder. Journal of Abnormal Child Psychology, 28(2), 205-211.

Bögels, S., \& Mansell, W. (2004). Attention processes in the maintenance and treatment of social phobia: hypervigilance, avoidance and self-focused attention. Clinical Psychology Review, 24, 827-856.

Bögels, S. M., Snieder, N., \& Kindt, M. (2003). Specificity of dysfunctional thinking in children with symptoms of social anxiety, separation anxiety and generalized anxiety. Behaviour Change, 20(3), 160-169.

Bradley, M. M., \& Lang, P. J. (1994). Measuring emotion: the selfassessment manikin and the semantic differential. Journal of Behavior Therapy and Experimental Psychiatry, 25(1), 49-59.

Brückl, T. M., Wittchen, H.-U., Höfler, M., Pfister, H., Schneider, S., \& Lieb, R. (2007). Childhood separation anxiety and the risk for subsequent psychopathology: Results from a community study. Psychotherapy and Psychosomatics, 76, 47-56.

Cartwright-Hatton, S., McNicol, K., \& Doubleday, E. (2006). Anxiety in a neglected population: prevalence of anxiety disorders in preadolescent children. Clinical Psychology Review, 26(7), 817-833.

Dalgleish, T., Taghavi, R., Neshat-Doost, H., Moradi, A., Canterbury, R., \& Yule, W. (2003). Patterns of processing bias for emotional information across clinical disorders: A comparison of attention, memory, and prospective cognition in children and adolescents with depression, generalized anxiety, and posttraumatic stress disorder. Journal of Clinical Child and Adolescent Psychology, 32(1), 10-21.

Eysenck, M. W. (1992). Anxiety: The cognitive perspective. Hove: Erlbaum.

Field, A. P. (2006). Watch out for the beast: fear information and attentional bias in children. Journal of Clinical Child and Adolescent Psychology, 35(3), 431-439.

Field, A. P., \& Lawson, J. (2003). Fear information and the development of fears during childhood: effects on implicit fear responses and behavioural avoidance. Behaviour Research and Therapy, 41, 1277-1293.

Field, A. P., \& Lawson, J. (2008). The verbal information pathways to fear and subsequent causal learning in children. Cognition and Emotion, 22(3), 459-479.

Garner, M., Mogg, K., \& Bradley, B. P. (2006). Orienting and maintenance of gaze to facial expressions in social anxiety. Journal of Abnormal Psychology, 115(4), 760-770.

Grawe, K., Donati, R., \& Bernauer, F. (1994). Psychotherapie im Wandel. Von der Konfession zur Profession. Göttingen: Hogrefe.

Hadwin, J., Frost, S., French, C. C., \& Richards, A. (1997). Cognitive processing and trait anxiety in typically developing children: evidence for an interpretation bias. Journal of Abnormal Psychology, 106, 486-490.

Hadwin, J. A., Garner, M., \& Perez-Olivas, G. (2006). The development of information processing biases in childhood anxiety: a review and exploration of its origins in parenting. Clinical Psychology Review, 26, 876-894.

Hermans, D., Vansteenwegen, D., \& Eelen, P. (1999). Eye movement registration as a continuous index of attention deployment: data from a group of spider anxious students. Cognition and Emotion, 13(4), 419-434. 
In-Albon, T., \& Schneider, S. (2007). Psychotherapy of childhood anxiety disorders: a meta-analysis. Psychotherapy and Psychosomatics, $76,15-24$.

In-Albon, T., \& Schneider, S. (2009). Using eye tracker methodology in children with anxiety disorders. In J. A. Hadwin \& A. P. Field (Eds.), Information processing biases in child and adolescent anxiety (Chapter 6). Chichester: Wiley.

In-Albon, T., Klein, A., Rinck, M., Becker, E., \& Schneider, S. (2008). Development and evaluation of a new paradigm for the assessment of anxiety disorder-specific interpretation bias using picture stimuli. Cognition and Emotion, 22(3), 422-436.

In-Albon, T., Dubi, K., Rapee, R. M., \& Schneider, S. (2009). Forced choice reaction time paradigm in children with separation anxiety disorder, social phobia and nonanxious controls. Behaviour Research and Therapy. doi:10.1016/j.brat.2009.08.003

Just, M. A., \& Carpenter, P. A. (1976). Eye fixations and cognitive processes. Cognitive Psychology, 8(4), 441-480.

Kendall, P. C. (1985). Toward a cognitive-behavioral model of child psychopathology and a critique of related interventions. Journal of Abnormal Child Psychology, 13, 357-372.

Kessler, R. C., Berglund, P., Demler, O., Jin, R., Merikangas, K. R., \& Walters, E. E. (2005). Lifetime prevalence and age-of-onset distributions of DSM-IV disorders in the national comorbidity survey replication. Archives of General Psychiatry, 62, 593-603.

Kindt, M., Bögels, S., \& Morren, M. (2003). Processing bias in children with separation anxiety disorder, social phobia and generalized anxiety disorder. Behaviour Change, 20(3), 143-150.

Kovacs, M. (1981). Rating scales to assess depression in school-aged children. Acta Paedopsychiatrica, 46, 305-315.

LeDoux, J. (1996). The emotional brain. New York: Simon \& Schuster.

Lewinsohn, P. M., Holm-Denoma, J. M., Small, J. W., Seeley, J. R., \& Joiner, T. E. (2008). Separation anxiety disorder in childhood as a risk factor for future mental illness. Journal of the American Academy of Child and Adolescent Psychiatry, 47(5), 549-556.

Lonigan, C. J., Vasey, M. V., Phillips, B. M., \& Hazen, R. A. (2004). Temperament, anxiety, and the processing of threat-related stimuli. Journal of Clinical Child and Adolescent Psychology, 33(1), 8-20.

MacLeod, C. (1990). Mood disorders and cognition. In M. W. Eysenck (Ed.), Cognitive psychology: An international review. Chichester: Wiley.

MacLeod, C., \& Mathews, A. (1991). Biased cognitive operations in anxiety: accessibility of information or assignment of processing priorities. Behaviour Research and Therapy, 29, 599-610.

MacLeod, C., Mathews, A., \& Tata, P. (1986). Attentional bias in emotional disorders. Journal of Abnormal Psychology, 95, 15-20.

Martin, M., Horder, P., \& Jones, G. V. (1992). Integral bias in naming of phobia-related words. Cognition and Emotion, 6, 479-486.

Mathews, A. (1990). Why worry? The cognitive function of anxiety. Behaviour Research and Therapy, 28(6), 455-468.

Mathews, A., \& MacLeod, C. (1985). Selective processing of threat cues in anxiety states. Behaviour Research and Therapy, 23, 563-569.

Mathews, A., \& Mackintosh, B. (1998). A cognitive model of selective processing in anxiety. Cognitive Therapy and Research, $22,539-560$.

Mogg, K., \& Bradley, B. P. (1998). A cognitive-motivational analysis of anxiety. Behaviour Research and Therapy, 36, 809-848.

Mogg, K., \& Bradley, B. P. (2006). Time course of attentional bias for fear-related pictures in spider-fearful individuals. Behaviour Research and Therapy, 44, 1241-1250.
Mogg, K., Millar, N., \& Bradley, B. P. (2000). Biases in eye movements to threatening facial expressions in generalized anxiety disorder and depressive disorder. Journal of Abnormal Psychology, 109(4), 695-704.

Monk, C. S., Nelson, E. E., McClure, E. B., Mogg, K., Bradley, B. P., Leibenluft, E., et al. (2006). Ventrolateral prefrontal cortex activation and attentional bias in response to angry faces in adolescents with generalized anxiety disorder. American Journal of Psychiatry, 163, 1091-1097.

Moradi, A., Taghavi, R., Neshat-Doost, H., Yule, W., \& Dalgleish, T. (1999). The performance of children and adolescents with PTSD on the Stroop colour naming task. Psychological Medicine, 29, 415-419.

Muris, P., Kindt, M., Bögels, S. M., Merckelbach, H., Gadet, B., \& Mouleart, V. (2000). Anxiety and threat perception abnormalities in normal children. Journal of Psychopathology and Behavioral Assessment, 22, 183-199.

Muris, P., Rapee, R., Meesters, C., Schouten, E., \& Geers, M. (2003). Threat perception abnormalities in children: the role of anxiety disorders symptoms, chronic anxiety, and state anxiety. Journal of Anxiety Disorders, 17, 271-287.

Öhman, A., Flykt, A., \& Esteves, F. (2001). Emotion drives attention: detecting the snake in the grass. Journal of Experimental Psychology: General, 130, 466-478.

Pflugshaupt, T., Mosimann, U. P., von Wartburg, R., Schmitt, W., Nyffeler, T., \& Müri, R. M. (2005). Hypervigilance-avoidance pattern in spider phobia. Journal of Anxiety Disorders, 19, 105-116.

Pina, A. A., Silverman, W. K., Saavedra, L. M., \& Weems, C. F. (2001). An analysis of the RCMAS lie scale in a clinic sample of anxious children. Journal of Anxiety Disorders, 15, 443-457.

Reynolds, C. R., \& Richmond, B. O. (1978). What I think and feel: a revised measure of children's manifest anxiety. Journal of Abnormal Child Psychology, 6, 271-280.

Rinck, M., \& Becker, E. S. (2006). Spider fearfuls attend to threat, then quickly avoid it: evidence from eye movements. Journal of Abnormal Psychology, 115(2), 231-238.

Rohner, J.-C. (2002). The time-course of visual threat processing: high trait anxious individuals eventually avert their gaze from angry faces. Cognition and Emotion, 16(6), 837-844.

Schneider, S., Unnewehr, S., In-Albon, T., \& Margraf, J. (2008). Attention bias in children of patients with panic disorder. Psychopathology, 41, 179-186.

Schneider, S., Unnewehr, S., \& Margraf, J. (2009). Diagnostisches Interview psychischer Störungen im Kindes- und Jugendalter (Kinder-DIPS). Heidelberg: Springer.

Stiensmeier-Pelster, J., Schürmann, M., \& Duda, K. (2000). DepressionsInventar für Kinder und Jugendliche (DIKJ). Göttingen: Hogrefe.

Vasey, M. W., Daleiden, E. L., Williams, L. L., \& Brown, L. M. (1995). Biased attention in childhood anxiety disorders: a preliminary study. Journal of Abnormal Child Psychology, 23, $267-279$.

Waters, A. M., Lipp, O. V., \& Spence, S. H. (2004). Attentional bias toward fear-related stimuli: an investigation with nonselected children and adults and children with anxiety disorders. Journal of Experimental Child Psychology, 89, 320-337.

Williams, J. M. G., Watts, F. N., MacLeod, C., Mathews, A., \& Mathews, A. (1997). Cognitive psychology and emotional disorders (2nd ed.). New York: Wiley. 1988.

Yiend, J., \& Mathews, A. (2001). Anxiety and attention to threatening pictures. The Quarterly Journal of Experimental Psychology, $54 \mathrm{~A}$ (3), 665-681. 